\title{
HYPOGENE SPELEOGENESIS: HYDROGEOLOGICAL AND MORPHOGENETIC PERSPECTIVE
}

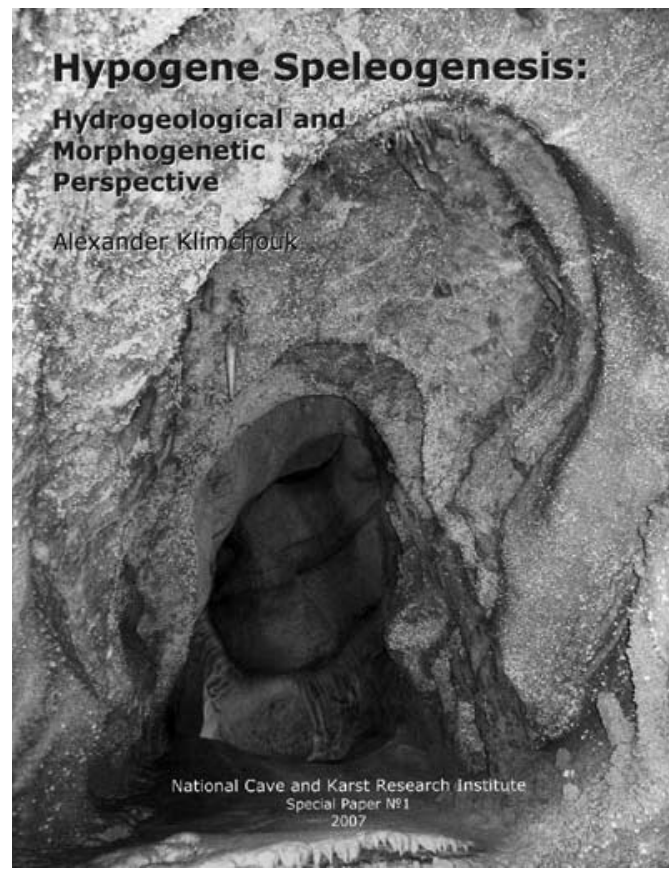

Alexander Klimchouk: Hypogene Speleogenesis: Hydrogeological and Morphogenetic Perspective. Cave and Karst Research Institute, Special Paper 1, vii + 106pp., National Cave and Karst Research Institute, Carlsbad NM, 2007.

The new book under review indicates that the turn of the millennium was an important milestone in the development of ideas related to speleogenesis, marking the beginning of a period that will completely change our understanding of the formation of the underground karst. Alexander Klimchouk is one of the few cave scientists who combines topmost scientific skills and knowledge with maximum physical caving condition. This enables him not only to consider the deepest problems of speleogenesis but also to visit even extremely difficult accessible caves and test his ideas on the spot.

The contents of this A4 format paperback book are arranged into five main sections, covering different aspects of hypogene speleogenesis. The book's scientific core is preceded by Contents, Foreword, List of Figures (62 in total), List of Plates (19 in total), List of Tables (2 in total), Abstract and Introduction and followed by an Epilogue, Acknowledgements and References (225 in total). Chapters and sections are numbered using decimal notation.

The Foreword by Dr. George Veni (Executive Director of the NCKRI) outlines the background of the book's conception and gestation. He concludes that: "...this book firmly establishes a new paradigm that will guide much karst research for decades to come."

The main chapter titles speak for themselves: Introduction, Basic concepts and terminology (1), Karst in the context of the systematized and hierarchical nature of regional groundwater flow (2), Ascending hypogenic speleogenesis (3), Hypogenic cave features (4), and Some implications of the hypogenic transverse speleogenesis concept (5). Rich in new ideas, the book challenges the very foundations of some current perceptions of understanding the karst. Its main value is the provision of a synthesis of the author's enormous practical knowledge of hypogene speleogensis and its related literature. Many informative and easily understandable figures support the straightforward reasoning within the text, which deepens the discussion of the notion of karst, while also widening its meaning. Another valuable facet is a lucid presentation and commentary upon existing definitions of karst and karstification, involving the ideas of several leading karstologists. A third positive aspect is discussion of virtually all possible cave morphological features, supported with clear photographs from around the world.

Whereas the personal authority stamped on the entire text by the author is close to being absolute, such a work could never be realized without the involvement 
and support of many individuals or institutions, as recognized by the warm thanks presented in the Acknowledgements. References are abundant, 225 in total per 99 pages of text (2.3 per page). Works written in English dominate, though Russian contributions form a significant part of the whole. This provides an invaluable insight into the relatively less well-known, though abundant, Russian karstological literature, and makes the text unusually well supported.

Perhaps weak points exist, even in so excellent a book, but more detailed dissection would reveal as many additional positive as possibly minor negative issues. In any case, as the reviewer is not specialized in this kind of speleogenesis, deeper analysis is omitted.

Slovene karstologists might ask whether such ideas - though of the utmost theoretical value - are applicable to the Slovenian karst, which is an example of epigene karst par excellence? In answering one must take Klimchouk's own assertion (p.2) very seriously: "Нyроgenic speleogenesis is much more widespread than it was previously presumed". The last few decades of research into Slovene underground karst genesis have pushed the beginning of karstification back by millions years. Only few, limited, cave systems can still be explained as products of straightforward sub-recent, processes. In reality it transpires that most of the best known cave systems are at least partially inherited from earlier stages, adapted to the present hydrological situation. Consequently, allowing for known rates of denudation, many channels were formed at far greater depths than previously expected.
Acceptance of this opens the way to application of the principles of hypogene speleogenesis within the classical karst of Slovenia. Some formerly problematical features, especially where tectonically conditioned ascending water circulation was implied, can now be reconsidered in the hypogene context. Hypogene speleogenesis might well turn out to be a highly relevant topic in Slovenia, as elsewhere, and will inevitably spawn a whole generation of new findings.

Only a few more words need be added. The book is an unavoidable "must" on the desks of theoreticallyoriented karstologists, as well as of more pragmatic hydrogeologists. One can only agree with the author (p.57): "The number of such caves recognized around the world is rapidly growing, and it is going to expand dramatically by re-interpretation of many caves, based on the new approach suggested in this book."

The book is available for $\$ 35$ plus $\$ 6$ domestic shipping or $\$ 13$ international shipping. Payable by Visa, MC, AMEX, or Discover cards via sales@nckri.org or by calling 001-505-835-6168, or by cheque written to "NCKRI" and sent to NCKRI/E\&ES, Attn: Lisa Majkowski, New Mexico Tech, 801 Leroy Place, Socorro, New Mexico, 87801 , USA. 